Caenorhabditis elegans has emerged as a powerful model organism for drug screening due to

its cellular simplicity, genetic amenability and homology to humans combined with its small

\section{Quantitative Analysis of Drug Efficacy on C. elegans Models for}

\author{
Neuromuscular Diseases
}

\author{
Samuel Sofela ${ }^{1,2}$, Sarah Sahloul $^{1}$, Yong-Ak Song ${ }^{1,2}$
}

${ }^{1}$ Division of Engineering, New York University Abu Dhabi, United Arab Emirates

${ }^{2}$ Tandon School of Engineering, New York University, USA

Keywords: C. elegans, drug screening, biophysical phenotyping, neuromuscular diseases.

\section{Abstract}

size and low cost. Currently, high-throughput drug screening assays are mostly based on image-based phenotyping not exploiting key locomotory parameters of this multicellular model with muscles such as its thrashing force, a critical parameter when screening drugs for muscle-related diseases. In this study, we demonstrated the use of a micropillar-based force assay chip in combination with an imaging assay to evaluate the efficacy of various drugs currently used in treatment of neuromuscular diseases. Using this two-dimensional approach, we showed that the force assay was generally more sensitive in measuring efficacy of drug treatment in Duchenne Muscular Dystrophy and Parkinson's Disease mutant worms as well as partly in Amyotrophic Lateral Sclerosis model. These results underline the potential of our 
bioRxiv preprint doi: https://doi.org/10.1101/2021.01.21.427562; this version posted January $21,2021$. The copyright holder for this preprint (which was not certified by peer review) is the author/funder, who has granted bioRxiv a license to display the preprint in perpetuity. It is made available under aCC-BY 4.0 International license.

force assay chip in screening of potential drug candidates for the treatment of neuromuscular diseases when combined with an imaging assay in a two-dimensional analysis approach.

\section{Introduction}

Neuromuscular diseases consist of a diverse group of medical conditions that mainly affect the one or more parts of the neuromuscular unit such as skeletal muscle, motor neurons, peripheral nerves and neuromuscular synapses[1]. These diseases which can be hereditary or acquired, affect as many as 1 in 3,000 people[2] and can be attributed to neurodegenerative diseases like Parkinson's disease (PD)[3] and Duchenne muscular dystrophies (DMD)[4]. A common effect of most neuromuscular disorders is locomotion due to muscle wasting, weakness and disuse[5].

Caenorhabditis elegans has been utilized as a relevant disease model to explain the intricacies of cellular processes and in the search for drugs for treatment of neuromuscular diseases[6]. In modeling of neuromuscular diseases, it is important that neuronal cellular functions and muscle structure are well conserved if drugs are to be translated to humans. As such, several drugs used in to treat neuromuscular and neurodegenerative diseases have proven effective in phenotyping C. elegans for validation[7-9].

Of particular interest is the locomotory mechanism of the $C$. elegans, which is involved in most of the worm's behavior, and has been used in genetic analysis to score phenotypes linked to neuromodulatory and structural defects[10]. The locomotory dynamics in C. elegans is not only derived from a combination of neuromuscular control systems but also from the coordination of internal control and physical properties of the worm[11,12]. Its locomotory behavior has mostly been quantified through measuring locomotive parameters, such as 
worm velocity, thrashing frequency, and number of bends[13]. While these parameters have proven beneficial, they are indirect phenotypes and provide a different aspect of worm physiology compared to force assays[14].

Due to the similar length scale, microfluidics technology has emerged as a powerful platform in the phenotyping of $C$. elegans[15-17]. Cornaglia et. al reported a multi-functional microfluidic platform for automated worm culture, immobilization and long-term imaging of Amyotrophic Lateral Sclerosis (ALS) and Huntington disease mutant worms[18]. In another study[19], long-term swimming exercise was used as a behavioral phenotype to understand the impact of exercise on locomotory performance in Alzheimer's and Huntington's disease model animals. Salam et al[20] utilized electrotaxis response of $C$. elegans to analyze the worm's response to neurotoxic and neuroprotective compounds in modeling PD. The aforementioned assays have contributed to better understanding and assessment of drug treatments for neuromuscular and neurodegenerative diseases. However, there was no direct characterization of muscle strength as the ability to generate the maximal amount of muscle force which can be correlated with clinical studies in humans. To this end, there have been several studies that quantified the force exerted by body wall muscles using elastomeric micropillars[21-24], however, only Hewitt et al used a neuromuscular disease model[14]. In their study, they reported the use of their micropillar-based force measurement system, called Nemaflex, to study the muscle strength of DMD mutant worms before and after drug treatment. Using their device with free-moving worms, they were able to show that adult $d y s-$ 1(eg33) mutants were weaker than wild-type worms while dys-1(cx18) mutants exhibited similar muscle force as wild-type worms. While these studies successfully quantified the muscle force, the use of free-moving worms could introduce complexities for tracking the 
worm which could pose major challenges for multiplexing. Although tracking of free-moving worms in micropillar array has been demonstrated[25], its throughput is still limited. In this study, we performed a two-dimensional analysis of drug efficacy using $C$. elegans as neuromuscular disease models. For the first-dimensional analysis, we utilized a microfluidic chip with an integrated array of elastomeric micropillars to partially immobilize a C. elegans and quantitatively measure its thrashing force before and after drug treatment. This thrashing force assay device in polydimethylsiloxane (PDMS) allowed us to quantify the force exerted by partially immobilized worms in various developmental stages independent of their trapping orientation[24]. To evaluate the muscle strength degradation in neuromuscular disease (NMD) model worms, we used three mutant worms: DMD (LS587), ALS (AM725), and Parkinson's Disease (NL5901). Using these models in the force assay device, we examined the efficacy of six representative drugs for the treatment of neuromuscular diseases. In the second-dimensional analysis, we performed a quantitative image analysis of the protein aggregation and morphological studies of the body wall muscles before and after drug treatment on an agarose pad following standard protocol and validated the force measurement data. In this way, we could quantify the efficacy of the drugs on the muscle force and corroborate the force data with morphological studies of the protein aggregation and actin filament structures in the body wall muscles for validation. With its simple and scalable design, our force assay chip has facilitated a highly quantitative and sensitive

87 biophysical phenotyping of $C$. elegans without biases to assess efficacy of various drugs on muscle strength. 
Three transgenic strains were used in this study to model neuromuscular diseases: LS587 (dysadult animals, eggs were allowed to hatch at room temperature except for LS587 strain which was kept at $15^{\circ} \mathrm{C}$.

For each strain, two different drugs were evaluated. For the DMD model, LS587, two common drugs were tested: prednisone and melatonin. Each drug was added to the Nematode Growth Media (NGM) with a final concentration of $0.37 \mathrm{mM}$ prednisone diluted in $0.062 \%$ DMSO and $1 \mathrm{mM}$ melatonin. Both drug concentrations were selected based on previous drug treatment study on C. elegans [14]. Worms grown on NGM mixed with the required drug starting from L1 stage for $\sim 3$ days and 17 hours at $15^{\circ} \mathrm{C}$ until L4 stage, and for 4 days and $\sim 17$ hours at $15^{\circ} \mathrm{C}$ until young adult stage. Control plates for prednisone contained 0.062\% DMSO.

110 ALS model worms were treated with doxycycline and riluzole at two different concentrations.

111 Doxycycline was added to the NGM plates to obtain a final concentration of $10.5 \mu \mathrm{M}$ and 32

$112 \mu \mathrm{M}$. Worms were cultured at $20^{\circ} \mathrm{C}$. The control group was kept for $\sim 2$ days and 4 hours to 113 reach young adult stage. The worms treated with $10.5 \mu \mathrm{M}$ doxycycline required additional $\sim 5$ 114 hours and those treated with $32 \mu \mathrm{M}$ doxycycline additional $\sim 9$ hours compared to the control 
group. This delay in growth is known as a side effect by doxycycline[18]. The higher dosage of doxycycline $(32 \mu \mathrm{M})$ was tested on SJ4100 and showed a decrease in the average size of aggregates[18]. For comparison, we also selected a lower dosage of the drug as well. Worms treated with riluzole were maintained at $20^{\circ} \mathrm{C}$ until L4 stage and then moved to liquid culture, the $\mathrm{S}$ basal medium containing the drug, until reaching young adult stage. Both the drug treated group and the control group contained 0.5\% DMSO which was used as a solvent for riluzole. The control sample was incubated for 1 day and 21 hours while for drug treated culture for drug treatment. In liquid culture, both the control and $30 \mu \mathrm{M}$ riluzole treated worms were incubated for $\sim 1$ day with shaking at $100 \mathrm{rpm}$ in $20^{\circ} \mathrm{C}$ in 96 well plate, while 100 $\mu \mathrm{M}$ riluzole treated ones required additional incubation by $\sim 3$ hours to reach young adult stage[13]. Riluzole treatment was shifted to liquid media in $\mathrm{S}$ basal due to the low solubility of riluzol in NGM similar to the study by Ikenaka et al.[13]. for the final concentrations of $0.7 \mathrm{mM}$ and $2 \mathrm{mM}$ with $0.5 \% \mathrm{DMSO}$ [27]. The control group also was treated with $0.5 \%$ DMSO. Worms were maintained at $20^{\circ} \mathrm{C}$ from $\mathrm{L} 1$ stage until young adult for $\sim 2$ days and 5 hours. Pramipexole was prepared in M9 buffer and spread on top of the NGM plates with a final concentration of $2.5 \mathrm{mM}$ and $5 \mathrm{mM} .5 \mathrm{mM}$ pramipexole has been reported in the treatment of C. elegans[28], and the lower dosage of $2.5 \mathrm{mM}$ was used

134 because excess amounts of pramipexole may result in over stimulation of $C$. elegans. Worms were grown for $\sim 2$ days and 5 hours at $20^{\circ} \mathrm{C}$ until reaching young adult stage. A summary of the culture methods and drug treatments can be found in S1 Table. 
bioRxiv preprint doi: https://doi.org/10.1101/2021.01.21.427562; this version posted January $21,2021$. The copyright holder for this preprint (which was not certified by peer review) is the author/funder, who has granted bioRxiv a license to display the preprint in perpetuity. It is made available under aCC-BY 4.0 International license.

The microfluidic device used in this paper was fabricated by conventional soft lithography

140

141

142

143

144

fps. Video analysis was performed using Kinovea ${ }^{\circledR}$ and deflections were measured every 10

160 frames (150 data points per micropillar) resulting in a total of 3600 data points per worm.

technique using polydimethylsiloxane (PDMS). It was reported in our previous paper (S1

Fig)[24]. Briefly, a silicon wafer was used as master mold and patterned using photolithography with the aid of a chrome mask. The mask was developed using a mask writer (Heidelberg Instruments DW66+). Sequel to patterning the silicon wafer, it was etched using deep reactive ion etching thereby creating holes and trenches that served as molds for the micropillars and channels respectively. The difference in heights between the channel and the micropillars was due to the loading effect.

To develop the microfluidic devices, PDMS polymer was prepared by mixing base and curing agents in a 10:1 weight ratio. The mixture was then degassed in a vacuum jar for $10 \mathrm{~min}$, dropcasted over the silicon master mold and cured in an oven for $\sim 4$ hours at $70{ }^{\circ} \mathrm{C}$. The cured PDMS replica was peeled off the silicon mold and carefully bonded on a glass slide after treatment with oxygen plasma for 2 min. Each device had an array of $2 \times 12$ micropillar array with $17.5-23.5 \mu \mathrm{m}$ in diameter, $36 \mu \mathrm{m}$ in height and channel depth of $45 \mu \mathrm{m}$. S1 Fig summarizes the geometrical details of each device and disease model applied to.

\section{Image Acquisition and analysis}

For the force assay, images and videos of the micropillar deflection due to worm thrashing were captured using an inverted bright-field microscope (Nikon ${ }^{\circledR}$ Eclipse Ti-U) equipped with a CCD camera (Andor ${ }^{\circledast}$ Clara E). The video of each worm was captured for 15 seconds at 100 Further details of the experimental set up can be found in our work[24]. 
bioRxiv preprint doi: https://doi.org/10.1101/2021.01.21.427562; this version posted January $21,2021$. The copyright holder for this preprint (which was not certified by peer review) is the author/funder, who has granted bioRxiv a license to display the preprint in perpetuity. It is made available under aCC-BY 4.0 International license.

The double mutant LS587 strain muscle morphology was examined with phalloidin (ThermoFisher, A12379) to stain actin filaments and evaluated closely under 60X immersion oil objective[24]. For NL5901 and AM725 protein aggregation was assessed through imaging using $3 \%$ agarose pads with $10 \mathrm{mM}$ levamisole then worms were imaged using $10 \mathrm{X}$ magnification with 10ms exposure time[29]. All imaging was carried out using FITC filter under inverted microscope (Nikon ${ }^{\circledR}$ Eclipse Ti-E) equipped with a CCD camera (Andor ${ }^{\circledR}$ iXon Ultra 897 EMCCD).

\section{Thrashing Force Measurement}

171 The thrashing force of the worms were measured using elastomeric micropillars incorporated within a microfluidic device. The microfluidic device, with the aid of a notch, partially immobilizes a part (head of tail) of the worm while the remainder of the body is allowed to thrash and consequently deflecting the micropillars. The deflection of the micropillars was captured and recorded for 15 secs. Due to the sensitivity of the micropillars, we observed non-linear deflection of same which implied that the conventional Timoshenko beam theory

177 could not be used for the calculation of forces. To calculate the thrashing force from non178 linear displacements, we used our custom finite element model (FEM) which we have 179 previously reported[24]. The maximum deflection of each micropillar was measured and the average was taken for the number of worms used. The finite element model was developed using ABAQUS/CAE 2016. The geometry was meshed using 20-noded quadratic hexahedral elements and analysis was performed with ABAQUS/Standard 2016 using a full-Newton direct solver. The effect of the PDMS soft substrate could be neglected, since the study focuses on the relative changes in the thrashing force only. Comparative analysis of the thrashing force was done using two-way ANOVA statistical technique. 
187 For comparison of thrashing force data, two-way ANOVA with Tukey's multiple comparison

was used. Changes in actin filament morphology of DMD worm samples were analyzed using using student t-test.

\section{Results}

193 The general workflow of the two-dimensional analysis is shown in Fig 1A. Once cultured on agarose plate and washed off using M9 solution, worms were split into two fractions. One fraction of the worm suspension was used for thrashing force analysis and the other fraction for image analysis. To quantify thrashing force, we used the PDMS-based micropillar force assay device shown in Fig 1B, which used a constriction channel to partially immobilize the worm. This partial immobilization circumvented vision-based tracking and introduced mechanical stimulation, induced by the walls of the constriction channel, on the head of the worm. The remainder of the worm thrashed on the micropillar array and the deflection was captured with a microscope (Fig 1C). Using a custom non-linear finite element model (see details in Methods section) the force exerted by the worms on each micropillar was calculated

(Fig 1D). We evaluated the thrashing force exerted by DMD (LS587), ALS (AM725) and

Parkinson's Disease (NL5901) mutant worms compared to wild-type N2. The average thrashing forces were $25.5 \pm 0.92 \mu \mathrm{N}$ (mean \pm standard error of the mean, $\mathrm{n}=27$ ), $7.9 \pm 0.49$ $\mu \mathrm{N}(\mathrm{n}=25), 11.4 \pm 1.43 \mu \mathrm{N}(\mathrm{n}=25)$ and $16.4 \pm 1.68 \mu \mathrm{N}(\mathrm{n}=25)$ for wild-type N2, LS587, AM725 
bioRxiv preprint doi: https://doi.org/10.1101/2021.01.21.427562; this version posted January 21,2021 . The copyright holder for this preprint (which was not certified by peer review) is the author/funder, who has granted bioRxiv a license to display the preprint in perpetuity. It is made available under aCC-BY 4.0 International license.

respectively. As for the second-dimensional analysis, we performed an image analysis using muscles and validated the force measurement data. analysis. The first dimensional analysis evaluated the change in thrashing force exerted by the worm before and after drug treatment. The second dimensional analysis used image analysis to evaluate the effect of drug treatment on morphology of the body wall muscles and protein aggregation. (B) Scanning electron micrograph of the force assay chip showing elastomeric micropillars. (C) Optical image showing a partially immobilized young adult worm thrashing on micropillars. (D) Non-linear finite element model used to calculate the thrashing force from the displacements of micropillars. The deflection of micropillars in the FEM image matches that of the optical image in (C). (E) Line graph showing thrashing forces of wild type N2, DMD, ALS and PD model worms in young adult stage. The disease model worms showed a $68.7 \%, 55.4 \%$ and $35.7 \%$ decrease in thrashing force for DMD, ALS and PD strains, respectively, compared to the thrashing force of wild-type N2.

\section{Melatonin and Prednisone improve thrashing force in DMD worm}

In C. elegans, the dys-1 gene encodes the protein orthologous to the dystrophin protein associated with DMD in humans which causes progressive muscle loss [30]. To increase the mutation, $h / h-1$ gene which is a homolog for the MyoD gene in human. Using the LS587 (dys-

230 melatonin and prednisone, on the recovery of the thrashing force in our force assay chip. 
bioRxiv preprint doi: https://doi.org/10.1101/2021.01.21.427562; this version posted January $21,2021$. The copyright holder for this preprint (which was not certified by peer review) is the author/funder, who has granted bioRxiv a license to display the preprint in perpetuity. It is made available under aCC-BY 4.0 International license.

patients [7] and has been reported to reduce the number of degenerate muscle cells in LS587 mutants[32].

In L4 worms, there was no significant difference in thrashing force with and without treatment for both drugs (Fig $2 \mathrm{~A}$ and Fig 2B). This insignificant change in thrashing force was expected because L4 worms have only $~ 5 \%$ degenerate muscle cells[33]. However, in young adult worms, both drugs significantly improved the thrashing force of the worm (Fig $2 \mathrm{C}$ and Fig 2D). The average thrashing force around the mid-region of the worm (pillars 5-9) was 9.1 $\pm 0.94 \mu \mathrm{N}(\mathrm{n}=25)$ and $9.9 \pm 0.35 \mu \mathrm{N}(\mathrm{n}=25)$ after treatment with melatonin and prednisone, respectively, which translated to a $21.3 \%$ and $40.1 \%$ improvement compared to untreated trapped, we observed a $18.8 \%$ and $22.2 \%$ increase in thrashing force for melatonin and prednisone, respectively. These results showed that thrashing force can be used as a phenotype to evaluate drug efficacy in muscle-related disease mutants at both larval and adult developmental stages.

Fig 2: Thrashing force assay in DMD model worm (LS587). (A) L4 stage DMD model worms did not show any significant change in thrashing force when treated with $1 \mathrm{mM}$ melatonin $(N=25, p>0.05)$. (B) Prednisone treatment on $\mathrm{L} 4$ model worms also did not show any change in thrashing force $(\mathrm{N}=25, \mathrm{p}>0.05)$. (C) Young adult worms treated with $1 \mathrm{mM}$ melatonin showed significant improvement in thrashing force exerted across all the micropillars when compared to control worms which were not treated $(\mathrm{N}=25, \mathrm{P}<0.0001)$. (D) Prednisone treatment also increased the thrashing force of young adult worms compared to worms without any treatment $(N=25, p<0.00001)$. Significant differences were analyzed using the two-way ANOVA with Tukey's multiple comparison between average force values of control and treated worms, error bars indicate s.e.m. 
bioRxiv preprint doi: https://doi.org/10.1101/2021.01.21.427562; this version posted January $21,2021$. The copyright holder for this preprint (which was not certified by peer review) is the author/funder, who has granted bioRxiv a license to display the preprint in perpetuity. It is made available under aCC-BY 4.0 International license.

was classified using a scoring scale from 0-2 (Fig 3A). A score of 0 indicated healthy parallel and smooth actin filaments while scores 1 and 2 demonstrated wave-like fibers (damaged) with minor waves for score 1 and major damage for score 2[35]. In L4 worms, there was no significant difference in muscle fibers after treatments with both drugs, melatonin $(n=29)$ and prednisone ( $n=27$ ) (Fig 3B and Fig 3 C). However, there was significant improvement in the morphology of muscle fibers of young adult worms when treated with prednisone $(n=$ 28), with $30 \%$ of worms recovering with score 0 (Figure 3c). Although there was an enhancement in muscle fibers of worms treated with $1 \mathrm{mM}$ melatonin $(n=35)$, it was not a significant difference.

Fig 3: Morphology study of body wall muscle actin filaments for DMD model worm (LS587). The effect of drug treatment with prednisone on muscle morphology in young adult (YA) was studied using phalloidin staining. (A) Score 0 for DMD strain after treatment with prednisone showing smooth and parallel muscle fibers, score 1 wave like filaments in control group (nontreated). (B) Treatment with $1 \mathrm{mM}$ melatonin for L4 stage and young adult stage both did not show any significant recovery $(p=0.49, p=0.12)$. (C) Treatment with $0.37 \mathrm{mM}$ prednisone in L4 stage did not show any significant recovery in muscle morphology $(p=0.54)$. However, in young adult a significant difference $(p=0.04)$ was measured. Significant differences were analyzed using chi-squared test. (Melatonin control, L4 stage, $\mathrm{N}=32$, drug treated $\mathrm{N}=29$; Melatonin control, $\mathrm{YA}, \mathrm{N}=30$, drug treated $\mathrm{N}=35$; prednisone control, $\mathrm{L} 4$ stage, $\mathrm{N}=30$, drug treated $\mathrm{N}=27$; prednisone control, $\mathrm{YA}, \mathrm{N}=31$, drug treated $\mathrm{N}=28$ ).

Riluzole shows dose dependent recovery of thrashing force

280 As the second disease model, we used a transgenic worm, AM725, for ALS which expresses SOD1 proteins in the body wall muscle cells. We quantified the response of the thrashing force of the worm to two drugs: riluzole and doxycycline. Riluzole has been shown to reduce 
bioRxiv preprint doi: https://doi.org/10.1101/2021.01.21.427562; this version posted January $21,2021$. The copyright holder for this preprint (which was not certified by peer review) is the author/funder, who has granted bioRxiv a license to display the preprint in perpetuity. It is made available under aCC-BY 4.0 International license.

disease progression and extend patients' survival by $3-6$ months[36]. Doxycycline has been used to improve the motility of worms and reduce oxygen consumption[18].

The AM725 mutant worms treated with $30 \mu \mathrm{M}$ of riluzole did not show any significant change in thrashing force compared to control worms seeded in the absence of the drug. However, when the concentration was increased to $100 \mu \mathrm{M}$, there was a significant increase in thrashing force. In the mid region of the worm (micropillars $5-9$ ), the average of the maximum thrashing force was $11.35 \pm 1.5 \mu \mathrm{N}(\mathrm{n}=25)$ and $14.37 \pm 1.44 \mu \mathrm{N}(\mathrm{n}=25)$ for control worms and those treated with $100 \mu \mathrm{M}$ riluzole, respectively (Fig 4A), indicating a $26.6 \%$ increase in thrashing force. With doxycycline, we observed an improvement in thrashing force for both concentrations of $10.5 \mu \mathrm{M}$ and $32 \mu \mathrm{M}$. The peak thrashing force, at the mid-region of worm, had average values of $7.13 \pm 0.1 \mu \mathrm{N}, 9.06 \pm 0.13 \mu \mathrm{N}$ and $9.38 \pm 0.1 \mu \mathrm{N}$ ( $\mathrm{n}=27$ for all samples) for worms seeded with 0 (control), $10.5 \mu \mathrm{M}$ and $32 \mu \mathrm{M}$ doxycycline, respectively (Fig 4B). These results implied a $27.1 \%$ and $~ 31.6 \%$ increase in thrashing force for $10.5 \mu \mathrm{M}$ and 32 $\mu \mathrm{M}$ doxycycline treatment, respectively. However, there was no significant difference in the thrashing force between the two doses of doxycycline. Within the reported dosages, only treatment with riluzole was dose-dependent.

Fig 4: Thrashing force assay in ALS model worm (AM725). (A) Mutant worms treated with $30 \mu \mathrm{M}$ riluzole did not show any significant change in thrashing force compared to untreated worms $(p>0.05)$. When the concentration of riluzole was increased to $100 \mu \mathrm{M}$, there was a significant increase in the measured thrashing force compared to control worms which were not treated with any drug ( $N=25, p<0.001)$. (B) Treatment with either $10.5 \mu \mathrm{M}$ or $32 \mu \mathrm{M}$ of doxycycline significantly improved the thrashing force of AM725 worm compared to control worms $(\mathrm{N}=27, \mathrm{p}<0.0001)$. However, there was no significant difference in the thrashing force at the two different concentrations of doxycycline. Significant differences were analyzed using the two-way ANOVA 
with Tukey's multiple comparison between average force values of control and treated worms, error bars

The incensement of mutated SOD1 expression in the worm's body wall muscle cells is an indicator of disease severity[37]. Fig 5A, Fig 5B and Fig 5C show fluorescent images of SOD1 protein aggregate before $(n=34)$ and after treatment with $30 \mu M(n=33)$ and $100 \mu M(n=35)$ riluzole. For the analysis, the size, count, and total area of the protein aggregates were measured (S2 Table). After treatments at both concentrations, there was a significant and $56 \pm 4.2$, respectively, after treatment with $30 \mu \mathrm{M}$ and $100 \mu \mathrm{M}$ riluzole (Fig 5D) while the average area decreased from $0.5 \pm 0.04$ to $0.39 \pm 0.04$ and $0.3 \pm 0.03$, respectively. However, there was no significant difference in aggregates count between control and $30 \mu \mathrm{M}$ riluzole. However, with $100 \mu \mathrm{M}$ riluzole, there was a significant difference in average count which dropped from $20 \pm 0.9$ to $16 \pm 0.9$. As comparison, the force analysis (Fig $4 \mathrm{~A}$ ) did not show any significant difference between control and $30 \mu \mathrm{M}$. In terms of the aggregate average size, there was a decrease for both concentrations from $55 \pm 2.8$ to $50 \pm 2.1$ and $43 \pm 3.1$, respectively, but only $32 \mu \mathrm{M}$ doxycycline decreased significantly (Fig 5E). Doxycycline treatment significantly decreased the average count for treatments with $10.5 \mu \mathrm{M}$ and $32 \mu \mathrm{M}$ from $21 \pm 0.77$ to $19 \pm 0.67$ and $17 \pm 0.65$, respectively. For the average area there was no significant decrease for $10.5 \mu \mathrm{M}$ while treatment with $32 \mu \mathrm{M}$ doxycycline showed a significant decrease in the average area.

Fig 5: Quantitative analysis of morphology in ALS model (AM725). (A) SOD1 protein aggregates in ALS model before treatment $(n=35)$. (B) After treatment with $30 \mu M(n=33)$. (C) After treatment with $100 \mu M$ doxycycline 
bioRxiv preprint doi: https://doi.org/10.1101/2021.01.21.427562; this version posted January $21,2021$. The copyright holder for this preprint (which was not certified by peer review) is the author/funder, who has granted bioRxiv a license to display the preprint in perpetuity. It is made available under aCC-BY 4.0 International license.

331

332

333

334

335

336

337

338

339

340

341

342

343

344

345

346

347

348

349

350

351

352

353

354

changes in average size and area while its effect on the thrashing force was not significant. (E) After treatment with doxycycline in terms of aggregate size, count, and average area. In the case of doxycycline, $32 \mu \mathrm{M}(n=40)$ showed significant changes while $10.5 \mu \mathrm{M}(\mathrm{n}=39)$ showed no significant changes in terms of average size and area. Significant differences were analyzed using t-test, error bars indicate s.e.m.

Drug treatment improves thrashing force in PD model worm

Previous study[38] has observed alpha-synuclein ( $\alpha$-synuclein), a small, predominantly presynaptic cytoplasmic protein in the brain of PD patients. Naturally, C. elegans does not possess an $\alpha$-synuclein homolog, however, several transgenic strains have been created such as NL5901 which has human $\alpha$-synuclein aggregation fused YFP in the muscles of the worm.

Using this strain, we quantified the change in thrashing force of the worms after treatment with two pharmacological drugs, pramipexole and levodopa. Pramipexole, a dopamine agonist reported to improve depressive symptoms of PD patients[39], and levodopa, a dopamine precursor which has been the main therapy for PD patients[40].

Treatment of NL5901 worms with either drug showed recovery of thrashing force. Worms treated with $2.5 \mathrm{mM}$ and $5 \mathrm{mM}$ of pramipexole exerted an average thrashing force of 22.09 $\pm 0.31 \mu \mathrm{N}$ and $23.15 \pm 0.22 \mu \mathrm{N}$ (Fig 6A) around its mid-region (micropillars 5-9). Compared to the untreated worms (control) which exerted $16.48 \pm 0.41 \mu \mathrm{N}$ ( $\mathrm{n}=25$ for all samples), the results showed $34.1 \%$ and $40.5 \%$ increase in thrashing force for treatments with $2.5 \mathrm{mM}$ and $5 \mathrm{mM}$ of pramipexole, respectively. There was no significant difference in the thrashing force at both drug concentrations. Using levodopa, the average thrashing force increased from $16.34 \pm 0.08 \mu \mathrm{N}$ of the control group to $19.5 \pm 0.2 \mu \mathrm{N}$ and $21.8 \pm 0.22 \mu \mathrm{N}$ ( $\mathrm{n}=25$ for all samples) for worms treated at $0.7 \mathrm{mM}$ and $2 \mathrm{mM}$, respectively (Fig 6B). This translated to an increment of $19.3 \%$ and $33.3 \%$ with $0.7 \mathrm{mM}$ and $2 \mathrm{mM}$ levodopa treatments, respectively, 
bioRxiv preprint doi: https://doi.org/10.1101/2021.01.21.427562; this version posted January 21,2021 . The copyright holder for this preprint (which was not certified by peer review) is the author/funder, who has granted bioRxiv a license to display the preprint in perpetuity. It is made available under aCC-BY 4.0 International license.

355

indicating an increase in thrashing force with higher drug concentration. This result showed a dose-dependent improvement in thrashing force with levodopa while no such dosedependent recovery was observed with pramipexole.

Fig 6: Thrashing force assay in Parkinson Disease model worm (NL5901). (A) Treatment of NL5901 worms with both $2.5 \mathrm{mM}$ or $5 \mathrm{mM}$ of pramipexole significantly improved the thrashing force compared to untreated worms $(N=25, p<0.001)$. There was no significant difference in thrashing force of worms between the two concentrations of the drug. (B) With levodopa, there was significant change in thrashing force of worms treated with $0.7 \mathrm{mM}$ of the drug. The thrashing force further increased with an increase in levodopa concentration from $0.7 \mathrm{mM}$ to $2 \mathrm{mM}(\mathrm{N}=25, \mathrm{p}<0.0001)$. Significant differences were analyzed using the two-way ANOVA with Tukey's multiple comparison between average force values of control and treated worms, error bars indicate s.e.m.

In NL5901 C. elegans strain, the levels of $\alpha$-synuclein was measured by estimating the fluorescence intensity of YFP in the muscle cells[27]. When the strain was treated with pramipexole, there no significant difference in fluorescence intensity between control and $2.5 \mathrm{mM}$ treated worms $(\mathrm{n}=27)$ (Fig 7D). However, treatment with $5 \mathrm{mM}$ pramipexole $(\mathrm{n}=$ 24), there was significant decrease in the fluorescence intensity of the protein aggregates. Treatment with $0.7 \mathrm{mM}(\mathrm{n}=32)$ and $2 \mathrm{mM}(\mathrm{n}=31)$ levodopa did not show any significant difference in fluorescence signal intensity (Fig 7E).

Fig 7: Quantification of fluorescence intensity of $\alpha$-synuclein protein in NL5901. (A) Fluorescent image of $\alpha$ synuclein protein accumulation before treatment $(n=31)$. (B) after treatment with $2.5 \mathrm{mM}(n=27)$. (C) after treatment with $5 \mathrm{mM}(\mathrm{n}=24)$ pramipexole. (D) Fluorescence intensity of protein accumulation before and after treatment with pramipexole. (E) Fluorescence intensity of protein accumulation before $(n=35)$ and after treatment with levodopa $0.7 \mathrm{mM}(n=32)$ and $2 \mathrm{mM}(\mathrm{n}=31)$. Significant differences were analyzed using t-test, error bars indicate s.e.m. 


\section{Discussion}

382

383

384

385

386

387

388

389

390

391

392

393

394

395

396

397

398

400

401

402

403

\section{Duchenne Muscular Dystrophy}

In this study, we treated C. elegans DMD mutant (LS587) with prednisone and melatonin, and observed significant improvement in the thrashing force of young adult worms. However, there was no change observed in L4 worms as expected. A possible explanation for this result could be due to non-degeneration of muscle cells until after L4 stage as a result of cellular repairs which occur at the end of each larval stage and delay muscle cell damages till adulthood[32]. The significant improvement in young adult worms aligned with the prior studies that treated single mutant $d y s-1[14]$ and double mutant $d y s-1 ; h / h-1$ [32] worms with prednisone and/or melatonin. In particular, our results with partially immobilized worms were in close agreement with the outcomes of the study conducted Hewitt et. al.[14]which used the same dosage of drug treatment on free-moving dys-1(eg33) mutant worms. Patients treated with melatonin have been reported to decrease serum creatine kinase which indicates reduced muscle damage and oxidative stress[31]. Similar reduction in oxidative stress and improved redox status have also been reported in $\mathrm{mdx}$ mice treated with melatonin[31]. Prednisone is known to act against inflammatory processes in the muscles of DMD patients[41], however this cannot be investigated in C. elegans due to the lack of inflammatory-mediated amplification in the worm's degenerative muscles. Another and a study suggested the sarcolemma stabilization due to little alterations in plasma membrane of muscle cells as another mechanism through which prednisone acts[32]. The image analysis of muscle morphology for DMD model supported the thrashing force data that there was no significant difference observed until L4 stage for both drugs, melatonin and prednisone. Even worms treated with melatonin until young adult stage did not show a significant recovery in 
bioRxiv preprint doi: https://doi.org/10.1101/2021.01.21.427562; this version posted January $21,2021$. The copyright holder for this preprint (which was not certified by peer review) is the author/funder, who has granted bioRxiv a license to display the preprint in perpetuity. It is made available under aCC-BY 4.0 International license.

404

405

406

407

408

409

410

411

412

413

414

415

416

417

418

419

420

421

422

423

424

425

426

427

muscle morphology while the thrashing force assay detected a significant increase of the thrashing force once treated. In the case of prednisone, however, its muscle morphology improved significantly when treated until young adult stage. It has been reported that LS587 mutant treated with prednisone recovered its muscle morphology almost to healthy state[33]. This result suggested that the thrashing force analysis was more sensitive than the image analysis when detecting the efficacy of drugs.

\section{Amyotrophic Lateral Sclerosis}

Both riluzole, an internationally approved ALS drug, and doxycycline, an antibiotic, were able to improve the thrashing force of $C$. elegans. The specific mechanism through which riluzole acts is still unknown, but several neuroprotective properties have been ascribed to it, such as inhibition of presynaptic glutamate release and upregulation of the expression of growth factors[42,43]. Doxycycline has been reported to improve locomotion in worms through activation of mitochondrial unfolded protein $\left(U P R^{m t}\right)[18]$. A potential explanation for this working mechanism of doxycycline is due to the fact that mitochondrial accumulation of misfolded SOD1 has been reported as a potential trigger for motor neuron death. Our result was in agreement with the previous studies that have shown amelioration of loss of motility in ALS mutant worms through treatment with riluzole[13] and doxycycline[18]. The dose dependence of the thrashing force of worms treated with riluzole at $30 \mu \mathrm{M}$ and $100 \mu \mathrm{M}$ corroborated with the results from the previously reported study on worm speed[13]. Doxycycline significantly improved the thrashing force at both concentrations, $10.5 \mu \mathrm{M}$ and $32 \mu \mathrm{M}$. When evaluating the protein aggregates in terms of count, size and average area, riluzole, was more effective with higher dosage of $100 \mu \mathrm{M}$ compared to $30 \mu \mathrm{M}$ in agreement with the thrashing force measurement. The average count of aggregates decreased 
bioRxiv preprint doi: https://doi.org/10.1101/2021.01.21.427562; this version posted January $21,2021$. The copyright holder for this preprint (which was not certified by peer review) is the author/funder, who has granted bioRxiv a license to display the preprint in perpetuity. It is made available under aCC-BY 4.0 International license.

significantly after treatment with $100 \mu \mathrm{M}$ of riluzole but not with $30 \mu \mathrm{M}$. In terms of average size and area, there was a significant decrease when treated with both $30 \mu \mathrm{M}$ and $100 \mu \mathrm{M}$ of riluzole. In comparison, the force measurement showed no effect of the drug at $30 \mu \mathrm{M}$. This result implied that the image analysis can also be more sensitive to the changes due to drug treatment than the force analysis. This finding proved the complementarity of both analyses when quantifying the drug efficacy. Doxycycline has been reported to decrease the size of SOD1 protein aggregate but not the aggregate count for SJ4100 strain[18]. In this study, doxycycline treatment decreased both the size and count of the protein aggregates significantly at $32 \mu \mathrm{M}$ but not at $10.5 \mu \mathrm{M}$ whereas the force analysis could discern a subtle change at the lower drug concentration.

\section{Parkinson's Disease}

440 Drug treatment of the PD model with pramipexole and levodopa showed an improvement in

441 thrashing force for both drugs. However, pramipexole showed a better recovery in thrashing

442 force compared to levodopa. In clinical trials, pramipexole has been reported to slow down

443 the onset of dopaminergic neurons in PD patients thereby improving the symptoms of the

444 disease[39]. Levodopa is the leading treatment for PD and has proved highly effective in 445 ameliorating symptoms of the disease[40]. The improvement of thrashing force exerted by

446 the worms treated with levodopa agrees with the prior studies on the locomotory parameters

447 of PD model worms with similar treatment[44]. A potential explanation for the effect of 448 levodopa is the increase in polarized distribution and expression of type-1 dopamine 449 receptors in acetylcholinergic motor neurons[44] compared to untreated worms. Our result 450 showed that the improvement of thrashing force is not dependent on drug dosage for 451 pramipexole at the concentration levels used in this study. For levodopa, however, there was 
454 locomotory parameter of PD C. elegans model. This result underscored the potential of pramipexole as treatment for PD considering the complications due to chronic use of levodopa[40]. When analyzing the protein accumulation by measuring the fluorescence intensity of YFP in the muscle cells, the fluorescence intensity decreased when treated with 5 $\mathrm{mM}$ pramipexole, but no significant difference was observed when treated with $2.5 \mathrm{mM}$. When treated with both concentrations of levodopa, $0.7 \mathrm{mM}$ and $2 \mathrm{mM}$, there was no significant difference measured. Compared to the thrashing force analysis which showed significant improvement with treatment of pramipexole or levodopa at both concentrations, the image analysis seemed to be less sensitive. In all three disease model cases, the force analysis seemed to be generally more sensitive than the image analysis and delivered a quantitative readout less ambiguous compared to the analysis of fluorescent images. However, our study also confirmed that both the thrashing force as well as the image analysis should be conducted together to validate the measurement data and to detect subtle changes in complementarity since one of them might be more sensitive than the other one depending on the disease models such as in ALS model.

\section{Conclusion}

471 To evaluate the efficacy of drug treatment on three $C$. elegans models for neuromuscular

472 diseases, we have implemented a two-dimensional workflow analysis consisting of a 473 thrashing force measurement in a microfluidic chip and an image analysis using an agarose 474 pad. In the first-dimensional analysis, we evaluated thrashing force of these disease model 
worms before and after drug treatment, while in the second-dimensional analysis, we performed a quantitative image analysis of the protein aggregation and morphological

477 studies of the body wall muscles. The thrashing force analysis was more sensitive to measure the changes resulting from drug treatment compared to the image analysis as demonstrated in the case of DMD and PD models and partially in ALS model. To the best of our knowledge, this was the first study that reported the force exerted by the body wall muscles of ALS and PD C. elegans models. All these results underlined the potential of our force assay chip in other muscle-related diseases. Our partial immobilization-based device reduced the complexities of instrumentation associated with tracking worms through computer vision. which offers scalability for multiplexing by using multiple parallel channels in the force assay chip. This multiplexing step in combination with an imaging chip for $C$. elegans could ultimately lead to higher throughput for drug screening.

\section{Conflicts of Interest}

There are no conflicts of interest to declare.

\section{Acknowledgements}

493 The authors will like to acknowledge support from Dr. Hala Fahs, Suma Gopinathan and

494 Fathima Refai of the Center for Genomics and Systems Biology, NYU Abu Dhabi in sourcing 
bioRxiv preprint doi: https://doi.org/10.1101/2021.01.21.427562; this version posted January 21,2021 . The copyright holder for this preprint (which was not certified by peer review) is the author/funder, who has granted bioRxiv a license to display the preprint in perpetuity. It is made available under aCC-BY 4.0 International license.

497

core facility for the device fabrication. This work was supported by the Al Jalila Foundation

498 [AJF201633]. S. Sofela was supported by the NYUAD Global PhD Fellowship program.

499

500

501 


\section{References}

503 1. McDonald CM. Physical activity, health impairments, and disability in neuromuscular disease. American Journal of Physical Medicine and Rehabilitation. 2002. doi:10.1097/00002060-200211001-00012

2. Sleigh JN, Sattelle DB. C. Elegans models of neuromuscular diseases expedite translational research. Transl Neurosci. 2010. doi:10.2478/v10134-010-0032-9

3. Srivanitchapoom P, Pandey S, Hallett M. Drooling in Parkinson's disease: A review. Parkinsonism and Related Disorders. 2014. doi:10.1016/j.parkreldis.2014.08.013

4. Bidkar PU, Satya Prakash MVS. Neuromuscular Disorders. Essentials of Neuroanesthesia. 2017. doi:10.1016/B978-0-12-805299-0.00045-2

5. Morris ME. Locomotor Training in People With Parkinson Disease. Phys Ther. 2006. doi:10.2522/ptj.20050277

6. Markaki M, Tavernarakis N. Modeling human diseases in Caenorhabditis elegans. Biotechnol J. 2010;5: 1261-1276. doi:10.1002/biot.201000183

7. Gaud A, Simon JM, Witzel T, Carre-Pierrat M, Wermuth CG, Ségalat L. Prednisone reduces muscle degeneration in dystrophin-deficient Caenorhabditis elegans. Neuromuscul Disord. 2004;14: 365-370. doi:10.1016/j.nmd.2004.02.011

8. Braungart E, Gerlach M, Riederer P, Baumeister R, Hoener MC. Caenorhabditis elegans MPP+ model of Parkinson's disease for high-throughput drug screenings. Neurodegener Dis. 2004;1: 175-183. doi:10.1159/000080983

522 9. Marvanova M, Nichols CD. Identification of neuroprotective compounds of caenorhabditis elegans dopaminergic neurons against 6-OHDA. J Mol Neurosci. 
10. Bono M de, Villu Maricq A. NEURONAL SUBSTRATES OF COMPLEX BEHAVIORS IN C.

ELEGANS. Annu Rev Neurosci. 2005;28: 451-501.

527 doi:10.1146/annurev.neuro.27.070203.144259

11. Berri S, Boyle JH, Tassieri M, Hope IA, Cohen N. Forward locomotion of the nematode C. elegans is achieved through modulation of a single gait. HFSP J. 2009;3: 1-9. doi:10.2976/1.3082260

12. Boyle JH, Berri S, Cohen N. Gait modulation in C. elegans: An integrated neuromechanical model. Front Comput Neurosci. 2012. doi:10.3389/fncom.2012.00010

13. Ikenaka K, Tsukada Y, Giles AC, Arai T, Nakadera Y, Nakano S, et al. A behavior-based drug screening system using a Caenorhabditis elegans model of motor neuron disease. Sci Rep. 2019;9: 1-10. doi:10.1038/s41598-019-46642-6

14. Hewitt JE, Pollard AK, Lesanpezeshki L, Deane CS, Gaffney CJ, Etheridge T, et al. model of Caenorhabditis elegans and its functional response to drugs. Dis Model Mech. 2018;11: dmm036137. doi:10.1242/dmm.036137

15. S. Sofela, A. Orozaliev, S.Sahloul, N. Chaturvedi, D. Shahjerdi, Y.-Ak Song D. Quantitative Analysis of Muscle Atrophy under Hyperglycemic Conditions using C. elegans Model in a Scalable Microfluidic Device. 22nd International Conference on Miniaturized Systems for Chemistry and Life Sciences. 2018. 
17. Sofela S, Sahloul S, Rafeie M, Kwon T, Han J, Warkiani ME, et al. High-throughput sorting of eggs for synchronization of C. elegans in a microfluidic spiral chip. Lab Chip. 2018;18: 679-687. doi:10.1039/C7LC00998D

18. Cornaglia M, Krishnamani G, Mouchiroud L, Sorrentino V, Lehnert T, Auwerx J, et al. Automated longitudinal monitoring of in vivo protein aggregation in neurodegenerative disease C. elegans models. Mol Neurodegener. 2016;11: 1-13. doi:10.1186/s13024-016-0083-6

19. Laranjeiro R, Harinath G, Hewitt JE, Hartman JH, Royal MA, Meyer JN, et al. Swim exercise in Caenorhabditis elegans extends neuromuscular and gut healthspan, enhances learning ability, and protects against neurodegeneration. Proc Natl Acad Sci. 2019;116: 23829-23839. doi:10.1073/pnas.1909210116

20. Salam S, Ansari A, Amon S, Rezai P, Selvaganapathy PR, Mishra RK, et al. A microfluidic phenotype analysis system reveals function of sensory and dopaminergic neuron signaling in C. elegans electrotactic swimming behavior. Worm. 2013;2: e24558. doi:10.4161/worm.24558

21. Johari S, Nock V, Alkaisi MM, Wang W. On-chip analysis of C. elegans muscular forces and locomotion patterns in microstructured environments. Lab Chip. 2013;13: 16991707. doi:10.1039/C3LC41403E

22. Khare SM, Awasthi A, Venkataraman V, Koushika SP. Colored polydimethylsiloxane micropillar arrays for high throughput measurements of forces applied by genetic model organisms. Biomicrofluidics. 2015;9: 014111. doi:10.1063/1.4906905

23. Rahman M, Hewitt J, Van-Bussel F, Edwards H, Blawzdziewicz J, Szewczyk N, et al. 
doi:10.1039/C8LC00103K

574

575

576

577

578

579

580

581

582

583

584

585

586

587

588

589

590

591

592

593

594

595

596

24. Sofela S, Sahloul S, Stubbs C, Orozaliev A, Refai FS, Esmaeel AM, et al. Phenotyping of Thrashing Forces Exerted by Partially Immobilized C. elegans using Elastomeric Micropillar Arrays. Lab Chip. 2019;19: 3685-3696. doi:10.1039/C9LC00660E

25. Qiu Z, Tu L, Huang L, Zhu T, Nock V, Yu E, et al. An integrated platform enabling optogenetic illumination of Caenorhabditis elegans neurons and muscular force measurement in microstructured environments. Biomicrofluidics. 2015;9: 014123. doi:10.1063/1.4908595

26. Stiernagle T. Maintenance of C. elegans. WormBook : the online review of C. elegans biology. 2006. pp. 1-11. doi:10.1895/wormbook.1.101.1

27. Chalorak $\mathrm{P}$, Jattujan $\mathrm{P}$, Nobsathian $\mathrm{S}$, Poomtong $\mathrm{T}$, Sobhon $\mathrm{P}$, Meemon K. Holothuria scabra extracts exhibit anti-Parkinson potential in C. elegans: A model for antiParkinson testing. Nutr Neurosci. 2018;21: 427-438.

doi:10.1080/1028415X.2017.1299437

28. Young AT, Ly KN, Wilson C, Lehnert K, Snell RG, Reid SJ, et al. Modelling brain dopamine-serotonin vesicular transport disease in Caenorhabditis elegans. Dis Model Mech. 2018;11: dmm035709. doi:10.1242/dmm.035709

29. Driscoll M. Mounting animals for observation with Nomarski DIC optics. WormBook. 2008.

30. Bessou C, Giugia J-B, Franks CJ, Holden-Dye L, Ségalat L. Mutations in the Caenorhabditis elegans dystrophin-like gene dys-1 lead to hyperactivity and suggest a link with cholinergic transmission. Neurogenetics. 1998;2: 61-72. doi:10.1007/s100480050053

31. Hibaoui Y, Reutenauer-Patte J, Patthey-Vuadens O, Ruegg UT, Dorchies OM. 
Melatonin improves muscle function of the dystrophic $\mathrm{mdx} 5 \mathrm{Cv}$ mouse, a model for Duchenne muscular dystrophy. J Pineal Res. 2011. doi:10.1111/j.1600079X.2011.00871.x

600

32. Brouilly N, Lecroisey C, Martin E, Pierson L, Mariol MC, Mounier N, et al. Ultrastructural time-course study in the C. elegans model for Duchenne muscular dystrophy highlights a crucial role for sarcomere-anchoring structures and sarcolemma integrity in the earliest steps of the muscle degeneration process. Hum Mol Genet. 2015;24: 6428-6445. doi:10.1093/hmg/ddv353

33. Brouilly N, Lecroisey C, Martin E, Pierson L, Mariol MC, Mounier N, et al. Ultrastructural time-course study in the C. elegans model for Duchenne muscular dystrophy highlights a crucial role for sarcomere-anchoring structures and sarcolemma integrity in the earliest steps of the muscle degeneration process. Hum Mol Genet. 2015;24: 6428-6445. doi:10.1093/hmg/ddv353

34. Gieseler K, Grisoni K, Ségalat L. Genetic suppression of phenotypes arising from mutations in dystrophin-related genes in Caenorhabditis elegans. Curr Biol. 2000;10: 1092-1097. doi:10.1016/S0960-9822(00)00691-6

35. Chuang H-S, Kuo W-J, Lee C-L, Chu I-H, Chen C-S. Exercise in an electrotactic flow chamber ameliorates age-related degeneration in Caenorhabditis elegans. Sci Rep. 2016;6: 28064. doi:10.1038/srep28064

36. Chen S, Sayana P, Zhang X, Le W. Genetics of amyotrophic lateral sclerosis: an update.

37. Dong L, Cornaglia M, Krishnamani G, Zhang J, Mouchiroud L, Lehnert T, et al. 
38. Spillantini MG, Crowther RA, Jakes R, Hasegawa M, Goedert M. -Synuclein in filamentous inclusions of Lewy bodies from Parkinson's disease and dementia with

39. Barone P, Poewe W, Albrecht S, Debieuvre C, Massey D, Rascol O, et al. Pramipexole randomised, double-blind, placebo-controlled trial. Lancet Neurol. 2010;9: 573-580. doi:10.1016/S1474-4422(10)70106-X

40. LeWitt PA, Fahn S. Levodopa therapy for Parkinson disease: Table. Neurology. 2016;86: S3-S12. doi:10.1212/WNL.0000000000002509

41. Mendell JR, Moxley RT, Griggs RC, Brooke MH, Fenichel GM, Miller JP, et al.

42. Doble A. The pharmacology and mechanism of action of riluzole. Neurology. 1996;47: 233S-241S. doi:10.1212/WNL.47.6_Suppl_4.233S

43. Mizuta I, Ohta M, Ohta K, Nishimura M, Mizuta E, Kuno S. Riluzole stimulates nerve growth factor, brain-derived neurotrophic factor and glial cell line-derived neurotrophic factor synthesis in cultured mouse astrocytes. Neurosci Lett. 2001;310: 117-120. doi:10.1016/S0304-3940(01)02098-5

44. Gupta DK, Hang X, Liu R, Hasan A, Feng Z. Levodopa-Induced Motor and Dopamine 


\section{Supporting Information}

646 S1 Fig, The microfluidic chip for quantifying thrashing force exerted by C. elegans. (A)

647 Optical image showing two developmental stages of worms ( $L 4$ and young adult) thrashing

648 on the PDMS-based micropillars. The deflection of the micropillars was used to quantify the

649 thrashing force exerted by the worm. (B) Table showing geometric parameters for force

650 assay chip and diameters of worms used in this study.

651

652 S1 Table, Summary of worm culture and drug treatments.

653

654 S2 Table, Summary of significance test of SOD1 protein aggregate quantification before

655 and after drug treatment.

656 

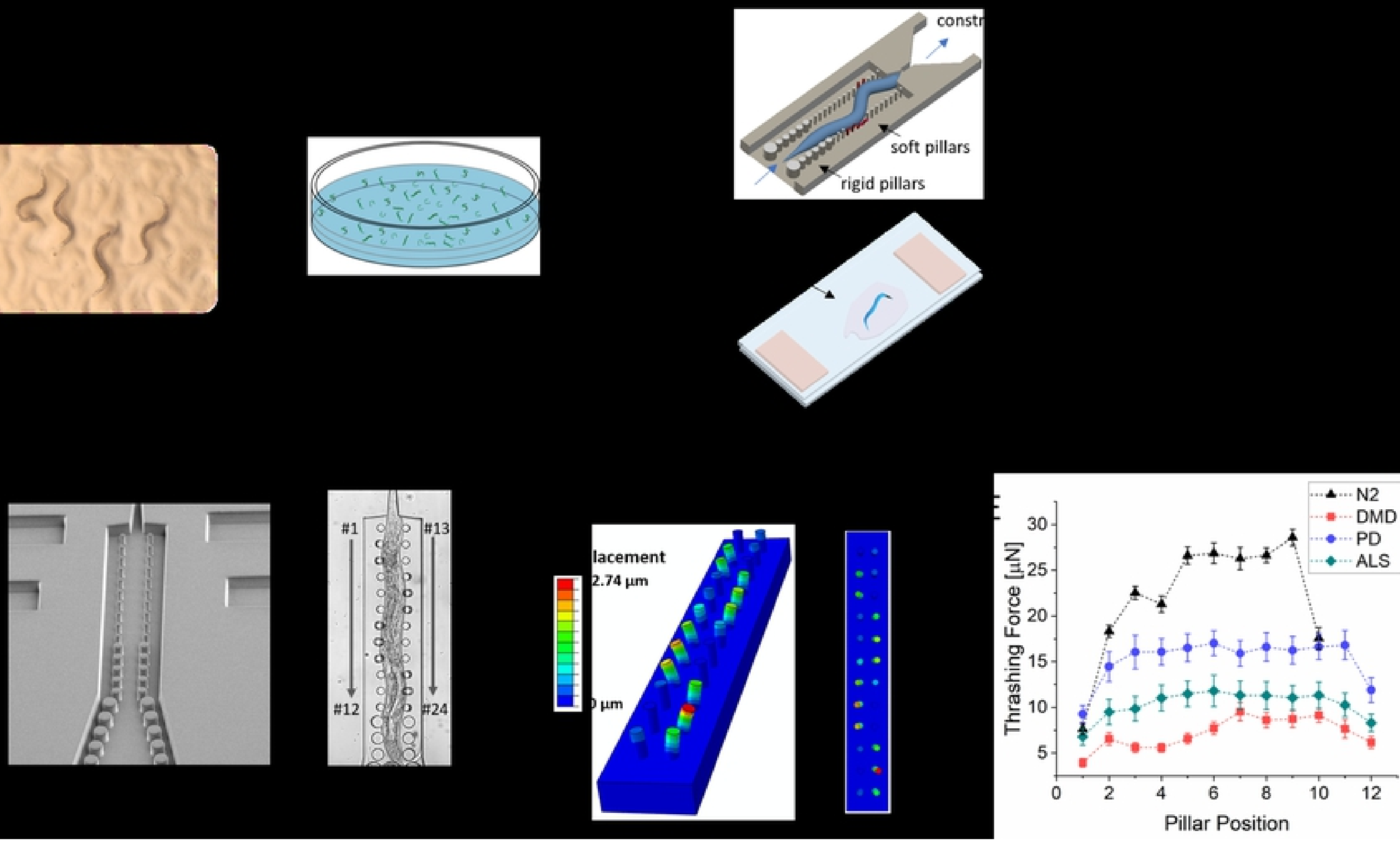

Fig1 

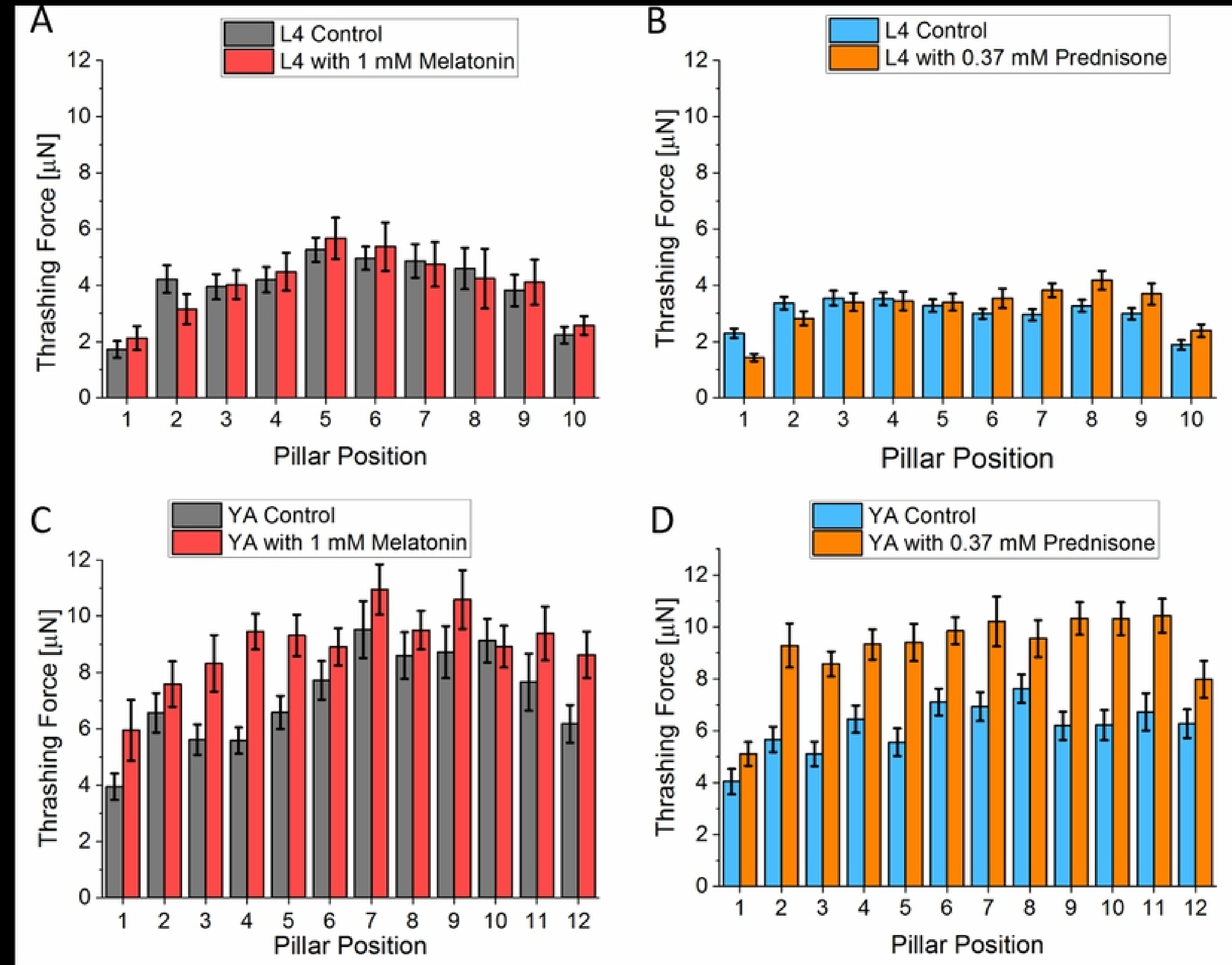

Fig2 

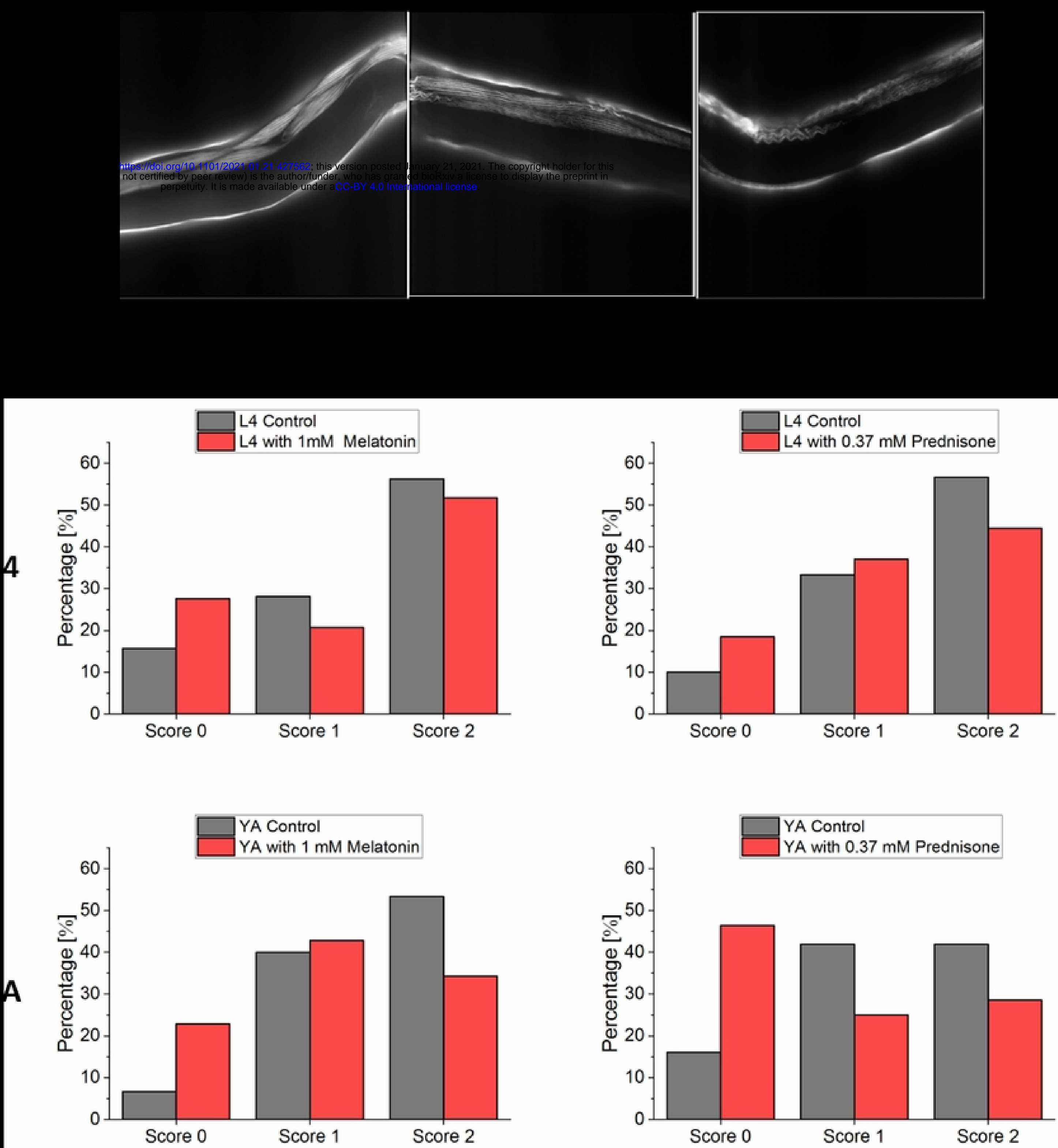

Fig3 


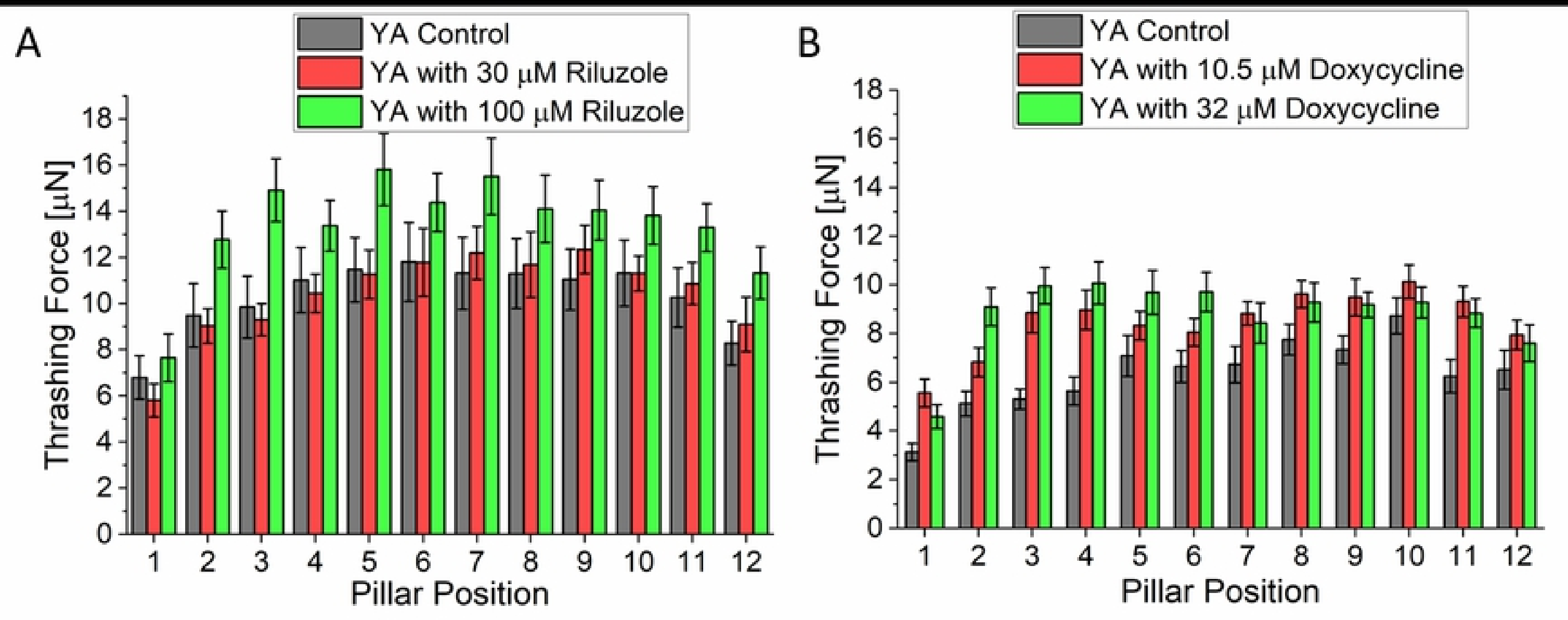

Fig4 

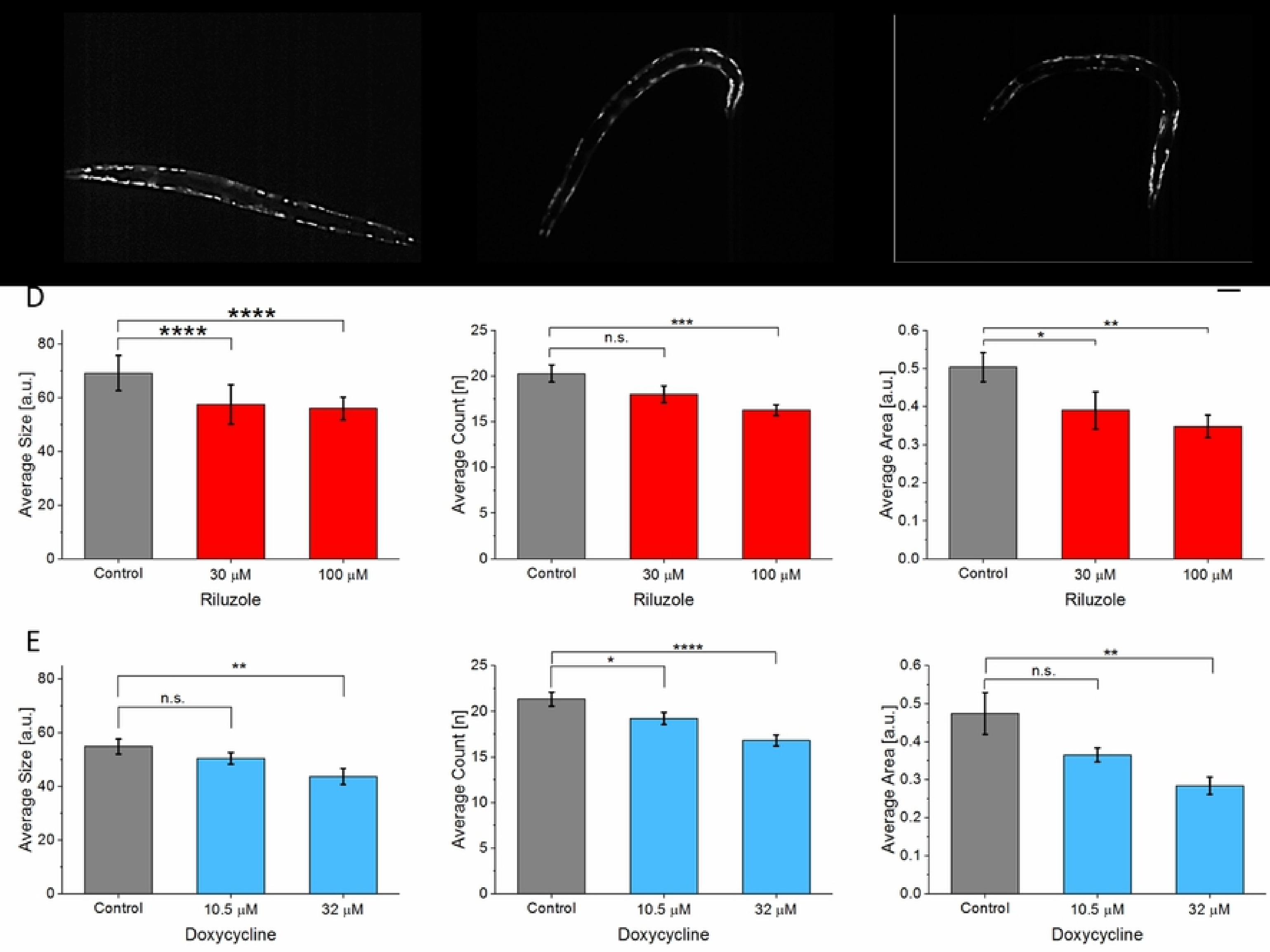

Fig5 

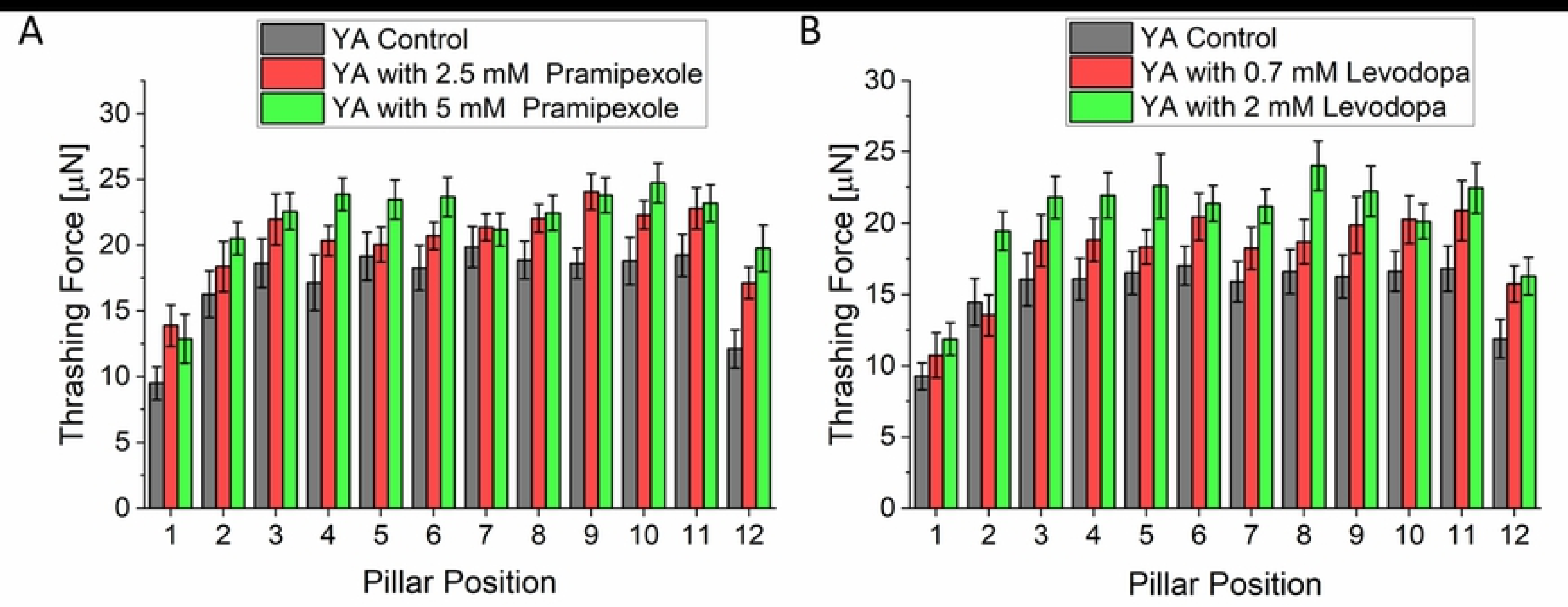

Fig6 

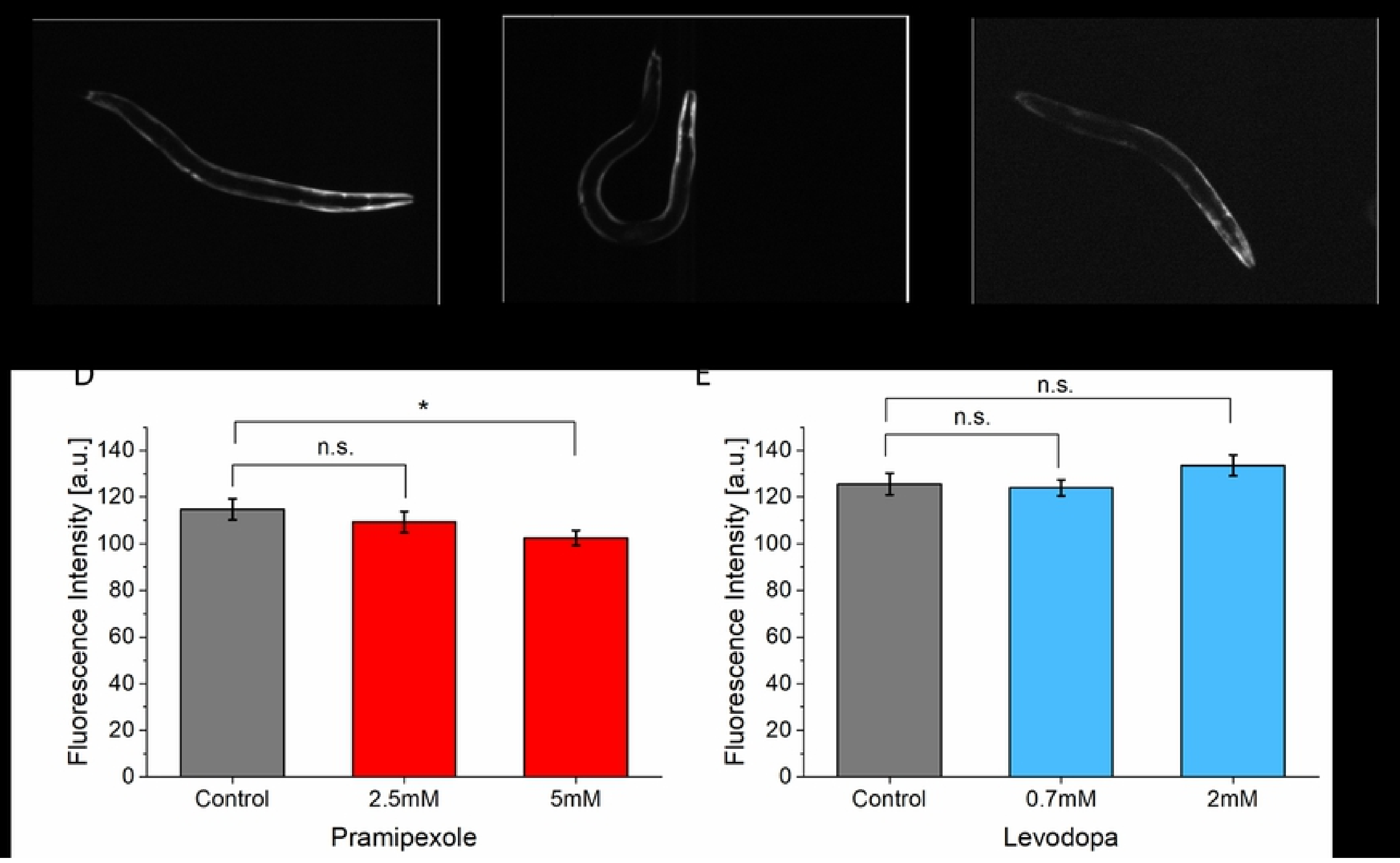

Fig7 